\title{
Immunology of food intolerance in adults
}

\author{
By RalPh Wright, Professorial Medical Unit, South Laboratory and Pathology \\ Block, Southampton General Hospital, Southampton $\mathrm{SO}_{9}{ }_{4} X Y$
}

\section{Introduction}

In recent years there have been major developments in the field of immunology impinging on every aspect of medicine. Gastroenterology is no exception and currently it is in this area that some of the most rapid advances are being made.

The gastrointestinal tract has an extensive mucosal surface with the capacity to absorb a variety of nutrient substances. Although significant absorption of large protein molecules for nutritional purposes does not occur in man, sufficient quantities of antigenic material are absorbed throughout life to produce and sustain an immune response, and the major stimulus to immunoglobulin production arises from intestinal colonization by viruses, bacteria and parasites and from the ingestion of dietary antigens.

\section{Normal immune responses in the gut}

Interest in the gut as a lymphoid organ was stimulated by the recognition that, in birds, stem cells develop in two discrete areas of central lymphoid tissue and differentiate into T-cells in the thymus and B-cells in the bursa of Fabricius. The B-cells in the bursa of Fabricius modulate antibody formation and bursectomy results in hypogammaglobulinaemia. The situation of the bursa of Fabricius adjacent to the cloaca prompted a search for the mammalian equivalent in the gastrointestinal tract. Recently, however, it has been shown that B-lymphocytes in the mammal develop in the foetal yolk-sac, liver, spleen and bone marrow and that the gut-associated lymphoid tissue contains both T- and B-lymphocytes capable of responding to antigenic stimulation (Owen, Cooper \& Raff, 1974).

A good example of the gut-associated lymphoid tissue is the Peyer's patches. They consist of nodules or germinal centres with an overlying flattened area heavily infiltrated with lymphocytes known as the dome area. The overlying epithelium adjacent to the lumen of the intestine contains a specialized epithelial cell type, the microfold or M-cells (Owen \& Jones, 1974). These M-cells permit lymphoid cells to approach the gut lumen very closely and make contact with intraluminal antigen. The Peyer's patches are seeded with T- and B-cells in the foetus, T-cells predominating before birth and B-cells proliferating in response to antigenic stimulation from the gut so that the proportion of $T$ - and B-cells will vary greatly with age.

It seems likely that antigen gains access to Peyer's patches through the specialized M-cells, that it interacts with T- and B- small lymphocytes in the $35(3) 3$ 
Peyer's patches in what is essentially a traffic area. Although they are immunoglobulin A $(\operatorname{Ig} A)$ precursor cells, the Peyer's patch cells do not produce $\operatorname{Ig} A$ locally. The sensitized cells then migrate to mesenteric lymph nodes undergoing a process of differentiation and develop the capacity to produce IgA locally in these nodes. Thereafter they enter the thoracic duct and, via the blood circulation, home selectively to the gut mucosa, where over $90 \%$ of lymphoid cells in the lamina propria are IgA-secreting plasma cells. The intra-epithelial lymphocytes are probably T-immunoblasts (Parrott, 1976).

Following earlier studies of the protective role of coproantibodies in cholera and dysentery, Tomasi, Tan, Solomon \& Prendergast (1965) showed that the immunoglobulin content of external secretions differs strikingly from that of serum, particularly in regard to IgA. This has resulted in the recognition of a secretory immunoglobulin system. There is good evidence that a local immune response including both secretory immunoglobulins and a cell-mediated response in the intestine may be important in the control of bacterial, viral and possibly fungal infections and in the elimination of parasites. Of greater interest in relation to the topic of gastrointestinal allergy is the possibility that the local immune response regulates dietary antigen absorption (Walker \& Isselbacher, 1974).

Dietary antigen absorption will depend upon a variety of factors in the adult in addition to the local immune response. These include intraluminal factors such as protein degradation by enzymes and hydrochloric acid, intestinal motility and a non-specific effect of secretory antibody preventing the adherence of antigen to the intestinal wall. Once the antigen is absorbed, the activity of lysosomes within the cell in handling antigen will also be important. Serum antibody and circulating lymphocytes may play a role particularly after there has been a break in the mucosal surface of the intestine. Once antigen has gained access to the intestinal cell, or systemic circulation, factors influencing the development of an allergic response and its nature are even more complex, and the reason why some individuals mount a normal response whereas in others it is a hypersensitive response is very poorly understood.

\section{Gastrointestinal hypersensitivity}

The allergic response to ingested antigens may be a type $\mathrm{I}$ or atopic reaction, an Arthus-type reaction or a response involving cell-mediated immunity. It may be local in the gastrointestinal tract, when it is known as gastrointestinal allergy, or the target organ may be remote from the gut, when the term alimentary allergy is often used (Truelove \& Wright, 1968).

Although the physician often sees patients who claim to be allergic to an item in the diet, it is important to exclude non-immunological causes of food intolerance. These include deficiencies of brush-border enzymes such as lactase ( $\beta$ galactosidase; $E C$ 3.2.1.23), either as a primary disorder or secondary to mucosal damage, or non-specific release of histamine from mast cells without involvement of reaginic antibody. 
Despite suggestive clinical evidence it is often difficult to determine whether a specific food is producing gastrointestinal symptoms on the basis of a hypersensitivity reaction. A variety of immunological tests have been used in an attempt to investigate this problem. In type I atopic allergy, skin tests to an extract of the allergen may be positive but usually these are non-contributory. Sublingual provocation tests, passive cutaneous anaphylaxis, basophil degranulation tests, the radio-allergosorbant (RAST) test and the release of histamine from human chopped lung in the presence of an extract of the allergen with patient's serum have also been used for testing for reaginic hypersensitivity.

Tests for cell-mediated hypersensitivity reactions have included lymphocyte transformation and leucocyte migration inhibition to specific antigens (May \& Alberto, 1972). All these tests, however, have strict limitations and are of little value in the individual patient.

The clinician is therefore faced with the problem of having to use methods such as dietary trials to identify the offending antigen. When one takes account of the wide variety of antigens present in the diet, this is often a monumental task. Rowe (1944) introduced the 'elimination diet'. By this method the patient starts on a basic diet from which foods which are known to be allergenic are removed and then if symptoms remit they are reintroduced. Another dietary method of identifying the antigen is by use of the food diary. By this method, the patient keeps a detailed record of all foods eaten at each meal together with symptoms and their time relationship to meals. Clearly this can be extremely difficult when the reaction is not of an immediate type.

Immunological methods may be combined with the use of dietary challenge. For example, peripheral blood eosinophilia and changes in the gastric mucosa after dietary challenge, observed by gastroscopy and, particularly, in combination with biopsy, may be useful. This may also be a useful method in studies of gastrointestinal milk allergy when it can be combined with small intestinal biopsy. The approach has, however, proved more useful in children (Shiner, Ballard \& Smith, 1975) than in adults.

\section{Coeliac disease}

In coeliac disease a potential antigen, gluten, has been clearly defined as a result of the classic studies of Dicke (1950). Elimination of gluten from the diet results in clinical and histological recovery and its reintroduction produces relapse. There are two main theories as to the pathogenesis of coeliac disease, one that it is due to the accumulation of a toxic polypeptide as a result of an enzyme defect and the other that it is a hypersensitivity response.

After challenge with gluten in a subject in whom there has been a good response to its exclusion, the earliest lesions occur within a few hours. They consist of swelling of endothelial cells of small blood vessels, oedema, and infiltration with inflammatory cells, including polymorphs, in the region of the basement membrane; a lesion which resembles an Arthus-type reaction. This progresses over a period of days to total or sub-total villous atrophy with infiltration of the lamina propria with lymphocytes, plasma cells and eosinophils. Villous atrophy may occur 
in other disorders and the terms 'coeliac disease' or 'gluten-sensitive enteropathy' should only be used if there is improvement of the intestinal lesion in response to a gluten-free diet and relapse on its reintroduction.

Coeliac disease is associated with dermatitis herpetiformis, fibrosing alveolitis, immunoglobulin deficiency and certain endocrine disorders, and we have recently reported an interesting association with external allergic alveolitis due to avian antigens (Berrill, Eade, Fitzpatrick, MacLeod, Hyde \& Wright, 1975). An increase in the incidence of other atopic disorders has been reported by some, but disputed by others.

Of interest from an immunological point of view is the association with lymphoreticular atrophy, particularly splenic atrophy. There is also an increase in the incidence of small intestinal lymphoma and of upper gastrointestinal carcinomas, particularly of the stomach and oesophagus (Harris, Cook, Thompson \& Waterhouse, 1967).

Immunological reactions. Immunological phenomena which are observed in coeliac disease include:

I. Serological abnormalities: antibodies to dietary proteins; antibodies to reticulin (untreated adults 50-70\%, untreated children 90-100\%); increased IgA, decreased IgM; selective IgA deficiency (rare); circulating immune complexes.

2. Mucosal abnormalities: deterioration after gluten challenge suggestive of an Arthus-type reaction; infiltration with immunologically competent cells; decreased $\operatorname{IgA}$, increased IgM; dietary and reticulin antibodies in jejunal juice.

3. Cell-mediated reactions: impaired lymphocyte PHA responsiveness; impaired lymphocyte cytotoxicity; in vitro CMI to gluten fractions.

4. Histocompatability antigens: increased incidence of HLA-B8 and HLA$\mathrm{DW}_{3}$.

5. Splenic and lymphoreticular atrophy.

6. Complicating lymphoma (rare).

Patients with coeliac disease have a high incidence of high-titre antibodies to gluten antigens as detected by haemagglutination or immunodiffusion, but similar reactions are seen to a variety of other dietary proteins, including purified milk protein and ovalbumin. These dietary antibodies can also be detected in intestinal juice and both serum and secretory antibodies fall in titre on a gluten-free diet. The most likely explanation is that they are a secondary phenomenon due to the absorption of intraluminal antigen through the damaged mucosa (Taylor, Truelove \& Wright, 1964).

Recently an antibody reacting with reticulin or basement membrane has been described in the sera of adults and children with coeliac disease (Alp \& Wright, 1971; Seah, Fry, Hoffbrand \& Holborow, 1971). The antibody is detected by indirect immunofluorescence and was initially reported in one-third to half of adult coeliacs. It tends to disappear on a gluten-free diet and in untreated coeliacs, it may be present in up to $70 \%$ of adults and almost all children with the disease (Stevens, Lloyd, Egan-Mitchell, Mylotte, Fottrell, Wright, McNicholl \& McCarthy, 1975). It is also present in about $25 \%$ of patients with dermatitis 
herpetiformis, in Crohn's disease in patients with selective IgA deficiency and rarely in apparently healthy adults. It is not clear whether the antibody is a secondary phenomenon due to absorption of dietary reticulin or whether it plays a role in pathogenesis.

Circulating serum IgA levels are often raised and immunoglobulin $M$ (IgM) levels lowered in untreated coeliac disease, with a return towards normality on a gluten-free diet. A decrease in the numbers of IgA-producing cells in the lamina propria has been reported, with an increase in IgM-producing cells, but it is likely that cells producing all the major immunoglobulin classes are increased (Brandtzaeg \& Baklin, 1976). There is an interesting association between coeliac disease and selective IgA deficiency but there is no evidence that the lesion in coeliac disease commonly results from a quantitative or qualitative defect in IgA.

Shiner \& Ballard (1972) have demonstrated the deposition of IgA and complement on the basement membrane within $12 \mathrm{~h}$ of gluten challenge, supporting the histological evidence suggesting an Arthus-type reaction. Additional evidence is the fall in the serum complement level and the demonstration of the Crq component in serum.

Cell-mediated immune reactions to gluten have been described using lymphocyte transformation and leucocyte migration inhibition techniques. The significance and specificity of these reactions are, however, questionable.

An alternative approach has been to use in vitro organ cultures of jejunal biopsies. When control and coeliac biopsies are cultured in the presence of gluten fractions, enzyme activity and growth are retarded in the coeliac biopsies but not in the controls; furthermore, the toxic effect of gluten is confined to biopsies from patients with active disease and is not observed in biopsies from patients in remission. Co-culture experiments have demonstrated a toxic effect of gluten on normal jejunal biopsies in the presence of biopsies from active coeliac disease. This suggests that a humoral mediator is released which has a toxic effect. Strober, Falchuk, Rogentine, Nelson \& Kleaveman (1975) have also claimed that the immunoglobulin produced by coeliac biopsies after gluten challenge consists largely of antibodies having anti-gluten specificity. These studies favour an immunological reaction rather than a direct toxic effect of gluten as a result of an enzyme defect.

If immunological mechanisms are important in the pathogenesis of coeliac disease, they may be mediated by an Arthus-type reaction, antibody-dependent lymphocyte cytotoxicity involving $\mathrm{K}$ cells (Killer cells) or a cell-mediated immune response. The pathogenesis of the lympho-reticular hypoplasia and the lymphoma which complicates coeliac disease is also uncertain. It has been suggested, based on evidence of impaired lymphocyte reactivity in coeliac disease, that this occurs because of defective immunological surveillance.

Whatever the pathogenesis of the disease, it is of interest that genetic factors appear to be important, as an increased incidence of histocompatability antigens HLA-B8 and HLA-DW 3 has been reported (Keuning, Pena, Van Leeuwen, Van Hooff \& Van Rood, r976). 


\section{Inflammatory bowel disease}

Ulcerative colitis and Crohn's disease are chronic disorders of the intestine of unknown aetiology with a tendency to remission and relapse. It is not known whether they represent two disorders of distinct aetiology or whether they are part of a spectrum with a varying tissue reactivity to a common aetiological agent. In addition there are a number of extra-intestinal manifestations, such as arthritis, ankylosing spondylitis, uveitis, erythema nodosum and liver disease, which may represent true complications of the inflammatory bowel disease, possibly independently mediated by immunological mechanisms, or they may form part of a generalized disease, the brunt of which falls on the intestine.

Andresen (1925) claimed, on the basis of elimination and challenge diets, that a high proportion of patients with ulcerative colitis have dietary allergy. He considered that cow's milk was the most important allergen but some patients appeared to be allergic to other foodstuffs such as wheat, eggs and fish.

The uncontrolled observations received support from a controlled clinical trial of various diets in ulcerative colitis (Wright \& Truelove, I965). Patients with ulcerative colitis in relapse were allocated at random to a milk-free diet, a milk-free plus gluten-free diet and a control group on a 'dummy' diet. They were asked to remain on the diets for a period of I year and were then allowed to return to a normal diet. Relapses were assessed on clinical and sigmoidoscopic grounds and patients who had three or more relapses during the period of I year or who could not be controlled by conventional treatment with corticosteroid drugs were considered to have failed and were withdrawn from the trial. Patients on a milkfree diet had significantly fewer relapses than those on a control diet. Several who had remained well on a milk-free diet for a period of I year relapsed when milk was reintroduced. It was estimated that approximately one in five patients who had remained symptom-free on a milk-free diet would have had repeated relapses on a normal diet. Blind assessment of the severity of inflammation in serial rectal biopsies from these patients showed that it was favourably modified by the milkfree diet. It is uncertain whether this effect is due to true milk allergy or whether it is due to lactose intolerance and there is little evidence on immunological grounds to support the possibility that this might be due to allergy. Circulating antibodies to purified milk proteins are likely to be a secondary phenomenon due to absorption of whole milk proteins through the damaged intestinal mucosa (Taylor et al. 1964) and studies of specific reaginic antibody using the erythrocyte-linked antigen antiglobulin test have been inconclusive (Jewell \& Truelove, 1972).

Support for the possibility that a type $\mathrm{I}$ reaction to some exogenous antigen might be operative in ulcerative colitis is provided by the finding of high circulating and tissue eosinophils in some patients in relapse. Recently there have been reports of a favourable response to oral and intra-rectal instillation of disodium cromoglycate, a drug which has a specific effect in stabilizing mast cells. The clinical response was most likely to occur in patients who had a high tissue eosinophil count (Heatley, Calcraft, Rhodes, Owen \& Evans, 1975). These authors have also reported an increase in the numbers of immunoglobulin $E$ (IgE)- 
producing cells in the rectal mucosa in idiopathic proctitis, although this has not been the general experience in more extensive ulcerative colitis. It is possible that a distinction needs to be made between distal proctitis in which atopic mechanisms may be operative and the more extensive ulcerative colitis which may be irreversible and which may have a different aetiology.

A wide variety of other immunological disturbances have been reported in ulcerative colitis. Of particular interest is the finding of circulating antibodies and cell-mediated immune responses to enterobacteria and the demonstration of crossreactivity between enterobacteria and the colonic epithelial antigen. Based on these observations it has been suggested that patients with ulcerative colitis develop an auto-immune response to the colon initiated by a response to the normal bacterial flora. Evidence for this interesting possibility is reviewed elsewhere (Whorwell \& Wright, 1976).

\section{Conclusions}

Despite rapid advances in our knowledge of the normal immune response in the gut, immunological methods for the study of dietary allergy are still primitive. Although dietary allergy may be suspected on clinical grounds in the adult, it is usually difficult to identify the offending allergen other than by elimination and challenge experiments. Such an approach has the major disadvantage that it cannot exclude the possibility that the response is occurring on the basis of a nonimmunological reaction.

In coeliac disease a potential antigen, gluten, has been identified as being causally related to the disorder but although a number of immunological phenomena have been reported, it is still possible that they are secondary to the disease process.

In ulcerative colitis there have been major difficulties in identifying a possible allergen, although some patients may benefit from the exclusion of milk. There is circumstantial evidence that a type $I$ allergic reaction may be operative in some cases of distal proctitis.

\section{REFERENCES}

Alp, M. H. \& Wright, R. (197r). Lancet ii, 682.

Andresen, A. F. R. (1925). Med. J. Rec. Suppl. 122, 271.

Berrill, W. T., Eade, O. E., Fitzpatrick, P. F., MacLeod, W. M., Hyde, I. \& Wright, R. (1975). Lancet ii, 1006.

Brandtzaeg, R. \& Baklin, K. (1976). Clin. Gastroenterol. 5, 251.

Dicke, W. K. (1950). Coeliac disease. An investigation into the harmful effect of various sorts of grain on the patient with coeliac disease. Doctoral Thesis, University of Utrecht.

Harris, O. D., Cook, W. T., Thompson, H. \& Waterhouse, J. A. H. (I967). Am. Y. Med. 42, 899.

Heatley, R. V., Calcraft, B. J., Rhodes, J., Owen, E. \& Evans, B. K. (1975). Gut 16, 559.

Jewell, D. P. \& Truelove, S. C. (1972). Gut 13, 796.

Keuning, J. J., Pena, A. S., Van Leeuwen, A., Van Hooff, J. P. \& Van Rood, J. R. (1976). Lancet i, 506.

May, C. D. \& Alberto, R. (1972). Int. Archs Allergy appl. Immun. 43, 525.

Owen, J. J. T, Cooper, M. D. \& Raff, M. C. (1974). Nature, Lond. 249, 361.

Owen, R. L. \& Jones, A. L., (1974). Gastroenterology 66, 189.

Parrott, D. N. V. (1976). Clin. Gastroenterol. 5, 211. 
Rowe, A. H. (1944). Elimination Diets; the Patient's Allergy. Philadelphia: Lea \& Febiger.

Seah, P. P., Fry, L., Hoffbrand, A. V. \& Holborow, E. J. (1971). Lancet i, 834.

Shiner, M. \& Ballard, J. (1972). Gut 14, 1.

Shiner, M., Ballard, J. \& Smith, M. E. (1975). Lancet i, 136 .

Stevens, F., Lloyd, R., Egan-Mitchell, B., Mylotte, M. J., Fottrell, P. F., Wright, R., McNicholl, B. \& McCarthy, V. F. (1975). Gut 16, 598 .

Strober, W., Falchuk, Z. M., Rogentine, G. N., Nelson, D. L. \& Kleaveman, H. L. (1975). Ann. intern. Med. 83, 242.

Taylor, K. B., Truelove, S. C. \& Wright, R. (1964). Gastroenterology 46, 99.

Tomasi, T. B., Tan, E. M., Solomon, A. \& Prendergast, R. A. (1965). f. exp. Med. 121, ror.

Truelove, S. C. \& Wright, R. (1968). In Clinical Aspects of Immunology, and ed., p. 1033 [R. G. H. Gell and R. R. A. Coombes, editors]. Oxford: Blackwell Scientific Publications.

Walker, W. A. \& Isselbacher, K. J. (1974). Gastroenterology 67, 53 I.

Whorwell, P. J. \& Wright, R. (1976). Clin. Gastroenterol. 5, 303.

Wright, R. \& Truelove, S. C. (1965). Gut $13,796$. 